\title{
1 Towards deciphering the structure of long homozygous stretches in cattle genome
}

\section{Michael Grigorievich Smaragdov}

3

4 Russian Research Institute of Farm Animal Genetics and Breeding - Branch

5 of the 1.K. Ernst Federal Science Center for Animal Husbandry, St. Petersburg,

$6 \quad$ Pushkin, Russian Federation. E-mail: spbvniigen@mail.ru

7 Corresponding author: M.G. Smaragdov e-mail: mik7252@yandex.ru

8

9

10

11

12

13

14

15

16

17 


\section{Abstract}

21 Up-to-day there is no as universally accepted software tool and threshold parameters to identify runs of homozygosity (ROH). The relative position of $\mathrm{POH}$ segments in the cattle genome has not been studied extensively. Specific objective of this study was to evaluate the effect of allowed missing and heterozygous SNPs in ROH on their number, on the estimate of inbreeding level, and on structure of ROH segments in the cattle genome. In this study 371 Holsteinized cows from six herds were genotyped with BovineSNP50 array. To identify $\mathrm{ROH}$, the consecutive and sliding runs were carried out with detectRUNS and Plink tools.

Neither effect was shown for missing SNPs genotype calls. Allowing even one heterozygous SNP resulted in significant bias of $\mathrm{ROH}$ data. Furthermore, the sliding runs identified less $\mathrm{ROH}$ than consecutive runs. The mean coefficient of inbreeding across herds was $0.111 \pm$ 0.003 and $0.104 \pm 0.003$ based on consecutive and sliding runs respectively. It was shown how, using the heterozygous SNPs in $\mathrm{ROH}$, may be possible to derive a distribution of $\mathrm{ROH}$ segments in the cow genome. We suggested it was similar to normal distribution. Furthermore, frequency of ROH in the chromosomes did not depend on their length. Of 29 chromosomes, the most abundant with ROH were BTA 14, BTA 7, and BTA 18. The result of this study confirmed more accurately identification of $\mathrm{ROH}$ with consecutive runs, uneven

37 their distribution in the cattle genome, significant bias of the data due to allowing heterozygous SNPs in ROH.

\section{Background}

40 Inbreeding in dairy cattle is an inevitable phenomenon of artificial selection. Traditionally coefficient of inbreeding is calculated based on ancestry [1]. With the advent of SNPs arrays become possible to investigate autozygosity at a previously unattainable level [2]. In fact, due 
to runs of homozygosity $(\mathbf{R O H})$ approach the analysis of the animal genome for extended homozygous SNPs stretches is still ongoing. The primary cause of autozygosity in livestock measured with $\mathrm{ROH}$ is assumed to be inbreeding [2] or consanguineous marriage in humans [3]. For identifying of $\mathrm{ROH}$, the softwares based on either identity by descent (IBD) GERMLINE [4], or Hidden Markov Model (HMM) Beagle [5] and BCFtools [6] were elaborated. An addition, the software based on scanning with SNPs window Plink [7], overlapping sliding window SNP101[8], or both consecutive and sliding runs detectRUNS [9] as well software based on other scripts [10,11], cgaTON [12] have been provided. There is the commercial software SNP \& Vriation Suite (Golden Helix SNP \& Variation Suite). It was shown that software based on HMM and IBD occurred to be inferior to other software mentioned above [13].The major difficulty faced by scientists is the lack of consistent criteria among studies regarding the threshold values in each parameters analyzed to define the $\mathrm{ROH}$ [2]. The most crucial parameters to be used in software are the number of allowed heterozygous or missing SNPs calls in ROH. There is inconsistency among thresholds to be applied in published studies. Some authors disallowed any number of heterozygous SNPs in $\mathrm{ROH}$ [14-17], other allowed one, two and more heterozygous SNPs depending on the length of ROH segments [18-25]. Anyway, Ferencakovic et al. [22] suggested that allowing some number of genotype errors in long $\mathrm{ROH}$ may minimize underestimation of those segments. Though, Mastrangelo et al. [24] showed small increasing in inbreeding coefficient, if heterozygous genotypes were allowed.

There are relatively a few studies assessing what a set of these parameters is optimal to detect $\mathrm{ROH}$, so as to better understand their effect on identified autozygosity. Ferencakovic et al. [22] have shown that SNP array density and genotyping errors introduce patterns of bias in the estimation of autozygosity. These authors observed that allowance of the heterozygous 
estimates of the $\mathrm{ROH}$ number. Based on simulation data Howrigan et al. [13] recommended

69

70 not allowing any heterozygous SNPs existence in a called ROH. Summarizing, there is currently no generally accepted opinion about the reasonable number of heterozygous SNPs in $\mathrm{ROH}$ to avoid bias in the $\mathrm{ROH}$ data.

The Leningrad region is the highest average milk yield producing region in Russia, with approximately 60,000 cows of Holsteinized Black and White cattle. Dutch, Danish, and Swedish Black and White bulls and heifers were imported to Russia during the 1930s. The Black and White breed was officially registered in Russia in 1959. To improve milk traits of Black and White cattle, local farmers started to use imported from USA (since 1978) and The Netherlands (since 2002) Holstein bulls and semen. Currently, the commercial Russian Black and White cattle population can be considered as Holstein due to long-term crossing only with Holstein bulls.

Main objectives of this study were: (i) to estimate the number of ROH segments in the cow genome with consecutive and sliding runs, (ii) to assess their dependence on allowed number of heterozygous and missing SNPs calls in $\mathrm{ROH}$, (iii) to quantify the coefficient of inbreeding of the cows in the herds studied, (iv) to compare the results obtained by these two approaches (v) to elucidate the structure and distribution of ROH in cow genome.

\section{Materials and Methods}

\section{Ethics statement}

This study does not involve any endangered or protected species. Samples were derived from the Committee on Agro-Industrial Complex of Leningrad region. The permission to carry out the sampling at each farm was obtained directly from the owners. All the samples were collected during routine veterinary checks and in accordance with local/national regulations 
and ethical rules in force at the time of sampling. The study was approved by the Ethical \&

92 Animal care committee of the RRIFAGB - Branch of the L. K. Ernst Federal Science

Centre for Animal Husbandry. Animals were handled with respect to the Russian Federal

94 Law No. 498-FZ on Responsible Treatment of Animals and on Amendments to Certain

95 Legislative Acts of the Russian Federation.

\section{Animal resources and SNPs genotyping}

97 Data and genotypes were obtained from Committee on Agro-Industrial Complex of

98 Leningrad region. Cows genotypes were available from six breeding herds located in

Leningrad region (Russia) born in range from 2010 to 2013. Animals for genotyping were selected by farmers with regarding the pedigree structure of the herd. Number of animals multiple daughters per single sire, the sires of dams were different. Sampled animals included $8-15 \%$ of total number of milking cows in herds. Altogether, 371 cows were genotyped with BovineSNP50 v.2.0 array (Illumina Ca. USA). In the first quality control step, SNPs with quality score less than 0.7 were removed. In the second step, genotyping quality control was done with PLINK 1.9 [7]. Only autosomal chromosomes were considered. In data set missing rate per SNP was no more than $5 \%$ and probability of deviation from Hardy-Weinberg equilibrium (HWE) was less than 1.0E-03. SNPs with MAF $<0.01$ were removed resulted in 48,108 SNPs. Total genotyping rate was $>0.99$.

\section{Detection the runs of homozygosity}

111 The ROH segments were identified using detectRUNS [9] implemented in R environment

112 [26], and Plink tool [7]. The parameters and threshold applied to define ROH with detectRUNS for consecutive runs method were: (i) minimal number of SNPs needed to 
define segment as a ROH: 15 and 20, (ii) number of missing calls allowed in a ROH segment: 0 - 4, (iii) number of heterozygous calls allowed in a ROH segment: 0 - 240, (iv) minimal

116 length of ROH segments: $250 \mathrm{~Kb}$, (v) maximal gap between $\mathrm{ROH}$ segments: $1 \mathrm{Mb}$.

117 For sliding window method the parameters and thresholds were: (i) window size: 15 SNPs and 20 SNPs, (ii) threshold: 0.05, (iii) minimal number of SNPs needed to define segment as

a ROH: 15 and 20, (iv) number of missing calls allowed in a ROH segment: 0 - 4, (v) number of heterozygous calls allowed in a $\mathrm{ROH}$ segment: 0 - 16, (vi) minimal length of ROH: $250 \mathrm{~Kb}$, (vii) maximal gap between $\mathrm{ROH}$ segments: $1 \mathrm{Mb}$, (viii) minimal allowed density of SNPs: 1 SNP per $1 \mathrm{Mb}$.

123 The parameters and threshold applied to define ROH with Plink were: (i) sliding window: 20 SNPs, (ii) the proportion of homozygous overlapping windows: 0.05 , (iii) the minimum number of SNPs in ROH: 20, (iv) density was one SNP per $50 \mathrm{~Kb}$, (v) the number of missing SNPs: zero, (vi) the number of heterozygous SNPs: zero.

127 Inbreeding coefficient was calculated as the sum of ROH length of an animal divided by the quantile (Q-Q) plot was performed in R environment [26].

\section{Results}

131 In this section the effect of the number of heterozygous and missing SNPs on ROH data was evaluated by consecutive and sliding runs. Primarily, the effect of missing SNPs allowed in $\mathrm{ROH}$ on the data was evaluated by consecutive and sliding runs. Both methods were not

134 show any effect on ROH data when from one to four missing SNPs calls were allowed in $135 \mathrm{ROH}$. Therefore, to evaluate the ROH findings further, this value has been fixed to zero. 


\section{Effect of heterozygous SNPs on ROH data}

\section{ROH identification based on consecutive runs}

138 To detect the number of ROH segments in the cow genome, 15 SNPs (S1 Table) and 20

139 SNPs (Table 1) consecutive runs across cows genome were carried out. When ROH segments

140 were not interrupted with heterozygous SNPs the mean number of ROH was greater in 1.9

141 times at 15 SNPs runs. In fact, the average number of $\mathrm{ROH}$ across herds was $182.0 \pm 2.8$ at

142 15 SNPs runs, as compared with $94.4 \pm 2.7$ at 20 SNPs runs. To avoid an autozygous ROH

143 overestimation due to short ROH segments, the 20 SNPs runs were used further.

144 Table 1. Estimated mean ( \pm SE) ROH number in the herds based on 20 SNPs

\section{consecutive runs}

\begin{tabular}{|c|c|c|c|c|c|c|}
\hline Herd & 1 & 2 & 3 & 4 & 5 & 6 \\
\hline \multicolumn{7}{|l|}{ 0* } \\
\hline $\begin{array}{l}\text { The mean } \\
\text { number of } \\
\text { ROH }\end{array}$ & $99.6 \pm 6.5$ & $90.5 \pm 1.0$ & $91.5 \pm 1.4$ & $106.4 \pm 14.7$ & $93.0 \pm 1.3$ & $91.4 \pm 1.5$ \\
\hline Maximum & 360 & 112 & 148 & 757 & 111 & 125 \\
\hline Minimum & 2 & 66 & 65 & 48 & 75 & 73 \\
\hline \multicolumn{7}{|l|}{1} \\
\hline $\begin{array}{l}\text { The mean } \\
\text { number of } \\
\text { ROH }\end{array}$ & $161.9 \pm 10.2$ & $145.4 \pm 1.3$ & $146.5 \pm 1.6$ & $155.8 \pm 12.1$ & $149.2 \pm 1.5$ & $148.8 \pm 1.6$ \\
\hline Maximum & 565 & 179 & 195 & 692 & 175 & 174 \\
\hline Minimum & 7 & 117 & 109 & 82 & 125 & 126 \\
\hline \multicolumn{7}{|l|}{2} \\
\hline $\begin{array}{l}\text { The mean } \\
\text { number of } \\
\text { ROH }\end{array}$ & $262.2 \pm 13.1$ & $243.1 \pm 1.6$ & $244.7 \pm 1.8$ & $253.7 \pm 7.4$ & $245.5 \pm 1.6$ & $248.2 \pm 1.8$ \\
\hline Maximum & 761 & 277 & 281 & 564 & 270 & 283 \\
\hline Minimum & 21 & 211 & 215 & 145 & 214 & 207 \\
\hline \multicolumn{7}{|l|}{4} \\
\hline $\begin{array}{l}\text { The mean } \\
\text { number of } \\
\text { ROH }\end{array}$ & $583.8 \pm 13.8$ & $573.6 \pm 2.1$ & $579.3 \pm 2.5$ & $582.7 \pm 7.4$ & $576.3 \pm 2.7$ & $580.3 \pm 3.3$ \\
\hline Maximum & 1017 & 625 & 631 & 655 & 636 & 630 \\
\hline Minimum & 116 & 528 & 536 & 383 & 533 & 525 \\
\hline \multicolumn{7}{|l|}{8} \\
\hline $\begin{array}{l}\text { The mean } \\
\text { number of }\end{array}$ & $1161.4 \pm 9.6$ & $1183.3 \pm 2.9$ & $1194.5 \pm 3.3$ & $1182.2 \pm 22.1$ & $1182.5 \pm 3.3$ & $1192.0 \pm 3.7$ \\
\hline
\end{tabular}




\begin{tabular}{|c|c|c|c|c|c|c|}
\hline $\mathrm{ROH}$ & & & & & & \\
\hline Maximum & 1227 & 1254 & 1271 & 1263 & 1233 & 1239 \\
\hline Minimum & 818 & 1126 & 1125 & 224 & 1129 & 1132 \\
\hline \multicolumn{7}{|l|}{16} \\
\hline $\begin{array}{l}\text { The mean } \\
\text { number of } \\
\text { ROH }\end{array}$ & $848.4 \pm 11.8$ & $857.1 \pm 2.1$ & $862.5 \pm 2.4$ & $852.2 \pm 16.8$ & $852.6 \pm 2.5$ & $860.3 \pm 2.9$ \\
\hline Maximum & 1297 & 914 & 898 & 1024 & 887 & 893 \\
\hline Minimum & 531 & 810 & 805 & 132 & 805 & 804 \\
\hline \multicolumn{7}{|l|}{20} \\
\hline $\begin{array}{l}\text { The mean } \\
\text { number of } \\
\text { ROH }\end{array}$ & $696.1 \pm 9.7$ & $703.4 \pm 1.7$ & $707.7 \pm 1.9$ & $699.4 \pm 13.8$ & $699.9 \pm 1.9$ & $706.3 \pm 2.3$ \\
\hline Maximum & 1069 & 753 & 738 & 840 & 732 & 735 \\
\hline Minimum & 417 & 668 & 659 & 107 & 664 & 663 \\
\hline \multicolumn{7}{|l|}{60} \\
\hline $\begin{array}{l}\text { The mean } \\
\text { number of } \\
\text { ROH }\end{array}$ & $257.2 \pm 3.4$ & $259.6 \pm 0.6$ & $261.2 \pm 0.7$ & $258.9 \pm 4.9$ & $258.2 \pm 0.7$ & $260.5 \pm 0.8$ \\
\hline Maximum & 390 & 275 & 272 & 312 & 260 & 272 \\
\hline Minimum & 160 & 248 & 242 & 49 & 248 & 244 \\
\hline \multicolumn{7}{|l|}{100} \\
\hline $\begin{array}{l}\text { The mean } \\
\text { number of } \\
\text { ROH }\end{array}$ & $163.9 \pm 2.1$ & $165.5 \pm 0.4$ & $166.3 \pm 0.5$ & $164.6 \pm 3.0$ & $164.5 \pm 0.5$ & $165.8 \pm 0.5$ \\
\hline Maximum & 247 & 174 & 176 & 195 & 173 & 173 \\
\hline Minimum & 103 & 156 & 157 & 38 & 155 & 157 \\
\hline \multicolumn{7}{|l|}{240} \\
\hline $\begin{array}{l}\text { The mean } \\
\text { number of } \\
\text { ROH }\end{array}$ & $80.9 \pm 0.9$ & $81.9 \pm 0.2$ & $82.2 \pm 0.2$ & $81.3 \pm 1.0$ & $81.5 \pm 0.3$ & $82.1 \pm 0.3$ \\
\hline Maximum & 114 & 87 & 86 & 93 & 87 & 86 \\
\hline Minimum & 55 & 77 & 78 & 36 & 77 & 77 \\
\hline
\end{tabular}

146 Note: * - The number of hetrozygous SNPs in ROH

147

148 Table 2. Estimated mean ( \pm SE) across herds ROH number in length classes based on 20

149 SNPs consecutive run

\begin{tabular}{c|l|l|l|l|l}
\hline Class (Mb) & \multicolumn{1}{|c|}{$0-2$} & \multicolumn{1}{|c|}{$2-4$} & \multicolumn{1}{|c}{$4-8$} & $6-16$ & \multicolumn{1}{c}{$>16$} \\
\hline $0^{*}$ & 3585 & 1155 & 662 & 319 & 113 \\
& \pm 277 & \pm 9 & \pm 63 & \pm 32 & \pm 17 \\
\hline 1 & 6792 & 1391 & 704 & 344 & 123 \\
& \pm 560 & \pm 103 & \pm 63 & \pm 34 & \pm 17 \\
\hline 2 & 12382 & 1840 & 750 & 362 & 131 \\
& \pm 1080 & \pm 142 & \pm 69 & \pm 31 & \pm 18 \\
\hline 4 & 31023 & 3552 & 874 & 395 & 139 \\
& \pm 2857 & \pm 308 & \pm 76 & \pm 31 & \pm 18 \\
\hline 8 & 59676 & 11991 & 1261 & 463 & 161 \\
& \pm 5699 & \pm 1084 & \pm 122 & \pm 34 & \pm 17 \\
\hline 16 & 16178 & 31742 & 4476 & 612 & 205 \\
& \pm 1570 & \pm 3010 & \pm 387 & \pm 65 & \pm 19 \\
\hline
\end{tabular}




\section{Note: * The number of allowed heterozygous SNPs in the ROH segments}

151 The effect of allowed heterozygous SNPs on the number of ROH segments was evaluated

152 when their values varied from 0 to 240 . Descriptive statistics of the data are given in Table 1 .

153 The mean number of ROH varied across herds. Nevertheless, between herds mean values

were insignificant when heterozygous SNPs were disallowed. The large variation of the ROH

number among the cows in fourth herd was observed. This result was due to large number of

$\mathrm{ROH}$ at one cow (757 ROH segments). Exclusion this cow resulted in the mean ROH number

157 for forth herd $85.9 \pm 2.1$. As a result, this herd, using t-test estimated with Bonferroni correction, became significantly differed from fifth herd $(\mathrm{P}<0.05)$. Initially, the average number of $\mathrm{ROH}$ increased by more than 10 times from $94.4 \pm 2.7$ up to $1182.7 \pm 4.9$ when

The length of $\mathrm{ROH}$ segments was classified into five categories (1-2 Mb, 2-4 Mb, 4-8 Mb, 8used (Table 2 vs. S2 Table). The largest proportion of ROH number had the same class up to eight allowed heterozygous SNPs, and then its proportion begun noticeable to decline (Table 2). The same type of the distribution was faithful for 2-4 Mb class but with other values of allowed heterozygous SNPs. Namely, the number of $\mathrm{ROH}$ began to increase when two heterozygous SNPs were allowed, then the distribution peaked at 16 heterozygous SNPs and

170 gradually decreased further (Fig 1). This type of distribution was the same for 4-8 Mb class 171 but with a lower maximum and at more number of allowed heterozygous SNPs. For 8-16 Mb 
172 class increasing of ROH number occurred when sixty heterozygous SNPs were allowed. The

173 mean length of ROH segments for each class is shown in S3 Table. These values did not

174 vary mach, except segments in $>16 \mathrm{Mb}$ class with 240 allowed heterozygous SNPs (S3

175 Table).

\section{ROH identification based on sliding runs}

177 As for consecutive runs, 15 SNP window (S4 Table) and 20 SNPs window (Table 3) for

178 sliding runs were used. Interestingly, the data for 15 SNPs runs identified both methods

179 nearly coincided (S1 Table vs. S4 Table) while for 20 SNPs runs the data differed

180 significantly in 1.9 times $(\mathrm{P}<0.001)$ (Table 1 vs. Table 3$)$. Therefore, for this approach as

181 well as consecutive runs, the shorter window was, the shorter ROH segments were identified.

182 Table 3. Estimated mean ( \pm SE) ROH number in the herds based on 20 SNPs sliding

183 runs

\begin{tabular}{|c|c|c|c|c|c|c|}
\hline Herd & 1 & 2 & 3 & 4 & 5 & 6 \\
\hline \multicolumn{7}{|l|}{ 0* } \\
\hline $\begin{array}{l}\text { The mean number } \\
\text { of } \mathrm{ROH}\end{array}$ & $\begin{array}{l}91 \\
\pm 6 \\
\end{array}$ & $\begin{array}{l}82 \\
\pm 1 \\
\end{array}$ & $\begin{array}{l}83 \\
\pm 1 \\
\end{array}$ & $\begin{array}{l}92 \\
\pm 14 \\
\end{array}$ & $\begin{array}{l}85 \\
\pm 1 \\
\end{array}$ & $\begin{array}{l}83 \\
\pm 1 \\
\end{array}$ \\
\hline Maximum & 336 & 194 & 138 & 731 & 106 & 111 \\
\hline Minimum & 1 & 62 & 59 & 44 & 67 & 64 \\
\hline \multicolumn{7}{|l|}{1} \\
\hline $\begin{array}{l}\text { The mean number } \\
\text { of } \mathrm{ROH}\end{array}$ & $\begin{array}{l}157 \\
\pm 9 \\
\end{array}$ & $\begin{array}{l}142 \\
\pm 1\end{array}$ & $\begin{array}{l}143 \\
\pm 1\end{array}$ & $\begin{array}{l}146 \\
\pm 5\end{array}$ & $\begin{array}{l}147 \\
\pm 1 \\
\end{array}$ & $\begin{array}{l}145 \\
\pm 1\end{array}$ \\
\hline Maximum & 513 & 174 & 175 & 335 & 175 & 169 \\
\hline Minimum & 5 & 117 & 114 & 82 & 118 & 120 \\
\hline \multicolumn{7}{|l|}{2} \\
\hline $\begin{array}{l}\text { The mean number } \\
\text { of } \mathrm{ROH}\end{array}$ & $\begin{array}{l}268 \\
\pm 10\end{array}$ & $\begin{array}{l}255 \\
\pm 1\end{array}$ & $\begin{array}{l}254 \\
\pm 2 \\
\end{array}$ & $\begin{array}{l}256 \\
\pm 4\end{array}$ & $\begin{array}{l}255 \\
\pm 2\end{array}$ & $\begin{array}{l}257 \\
\pm 2\end{array}$ \\
\hline Maximum & 631 & 284 & 287 & 294 & 285 & 288 \\
\hline Minimum & 21 & 225 & 220 & 109 & 237 & 222 \\
\hline \multicolumn{7}{|l|}{4} \\
\hline $\begin{array}{l}\text { The mean number } \\
\text { of } \mathrm{ROH}\end{array}$ & $\begin{array}{l}524 \\
\pm 8 \\
\end{array}$ & $\begin{array}{l}535 \\
\pm 2 \\
\end{array}$ & $\begin{array}{l}540 \\
\pm 2 \\
\end{array}$ & $\begin{array}{l}533 \\
\pm 12 \\
\end{array}$ & $\begin{array}{l}534 \\
\pm 2 \\
\end{array}$ & $\begin{array}{l}542 \\
\pm 3 \\
\end{array}$ \\
\hline Maximum & 576 & 578 & 586 & 608 & 579 & 590 \\
\hline Minimum & 133 & 494 & 484 & 39 & 492 & 502 \\
\hline \multicolumn{7}{|l|}{8} \\
\hline The mean number & 266 & 271 & 272 & 264 & 270 & 270 \\
\hline
\end{tabular}




\begin{tabular}{l|l|l|l|l|l|l}
\hline \multicolumn{1}{c|}{ of ROH } & \pm 8 & \pm 1 & \pm 2 & \pm 6 & \pm 2 & \pm 2 \\
\hline Maximum & 580 & 305 & 314 & 402 & 294 & 302 \\
\hline Minimum & 50 & 246 & 238 & 36 & 241 & 238 \\
\hline \multicolumn{1}{c|}{12} & & & & & & \\
\hline $\begin{array}{l}\text { The mean number } \\
\text { of ROH }\end{array}$ & $\begin{array}{l}43.3 \\
\pm 2.1\end{array}$ & $\begin{array}{l}41,3 \\
\pm 0.2\end{array}$ & $\begin{array}{l}41.3 \\
\pm 0.3\end{array}$ & $\begin{array}{l}41.5 \\
\pm 0.6\end{array}$ & $\begin{array}{l}40.4 \\
\pm 0.2\end{array}$ & $\begin{array}{l}41.1 \\
\pm 0.3\end{array}$ \\
\hline Maximum & 161 & 47 & 48 & 63 & 45 & 48 \\
\hline Minimum & 36 & 37 & 37 & 36 & 36 & 37 \\
\hline \multicolumn{1}{c}{16} & 36 & 36 & 36 & 36 & 36 & 36 \\
\hline $\begin{array}{l}\text { The mean number } \\
\text { of ROH }\end{array}$ & NA & NA & NA & NA & NA & NA \\
\hline Maximum & NA & NA & NA & NA & NA & NA \\
\hline Minimum & Naf
\end{tabular}

184 Note: * The number of allowed heterozygous SNPs in the ROH segments

185 To have a comparable result to consecutive runs, 20 SNPs window was used further.

186 Descriptive statistic for 20 SNPs sliding data is given in Table 3. Between herds mean

187 number of ROH was insignificant for disallowed heterozygous SNPs in ROH. But, similar to

188 consecutive runs after exclusion the most deviated cow (731 ROH segments) among fourth

189 herd, the mean number $\mathrm{ROH}$ became $77.6 \pm 2.0$ and fourth herd significantly differed from

190 third, fifth and sixth herds $(\mathrm{P}<0.02)$ using t-test estimated with Bonferroni correction. The

191 mean value increased six times from $86.0 \pm 2.6$ to $534.7 \pm 2.5$ when four heterozygous SNPs

192 in ROH were allowed, then decreased to 36 when the number of heterozygous SNPs

193 increased to sixteen.

194 The length of ROH segments were classified into the same five categories (1-2 Mb, 2-4 Mb,

195 4-8 Mb, 8-16 Mb, and >16 Mb) as it was done for consecutive runs (Table 4). The most

196 abundant in the number of $\mathrm{ROH}$ was $1-2 \mathrm{Mb}$ class as well. This fact indicates that with an

197 increase in the number of allowed heterozygous SNPs, initially the number of short 1-2 Mb

$198 \mathrm{ROH}$ had a bursting increase, and only then the number of longer ROH increased (Fig 2 ).

199 Hence, close location of numerous shorter than $1 \mathrm{Mb}$ ROH segments were identified in cow

200 genome. Like this, starting from two allowed heterozygous SNPs, 4-8 Mb ROH segments

201 began to increase, and starting from four heterozygous SNPs, 8-16 Mb and >16 Mb ROH 
segments likewise began to increase. Finally, only beyond eight heterozygous SNPs the

necessary to pay attention to a sizable increase in the average length of ROH segments in the

$>16 \mathrm{Mb}$ class when the number of allowed heterozygous SNPs exceeded 12 (S5 Table).

\begin{tabular}{c|l|l|l|l|l}
\hline Classes (Mb) & \multicolumn{1}{|c|}{$0-2$} & \multicolumn{1}{|c|}{$2-4$} & \multicolumn{1}{c|}{$4-8$} & $6-16$ & \multicolumn{1}{c}{$>$} \\
\hline $0^{*}$ & 3190 & 1048 & 643 & 309 & 111 \\
& \pm 241 & \pm 83 & \pm 61 & \pm 32 & \pm 16 \\
\hline 1 & 6488 & 1419 & 690 & 358 & 139 \\
& \pm 554 & \pm 122 & \pm 66 & \pm 31 & \pm 15 \\
\hline 2 & 12205 & 2444 & 817 & 385 & 152 \\
& \pm 1100 & \pm 220 & \pm 88 & \pm 39 & \pm 14 \\
\hline 4 & 22024 & 8342 & 2169 & 545 & 185 \\
& \pm 2139 & \pm 738 & \pm 208 & \pm 54 & \pm 19 \\
\hline 8 & 2744 & 3333 & 4421 & 3795 & 2476 \\
& \pm 267 & \pm 312 & \pm 447 & \pm 379 & \pm 226 \\
\hline 12 & 23 & 21.7 & 281 & 181 & 2071 \\
& \pm 3 & \pm 4.5 & \pm 24 & \pm 19 & \pm 193 \\
\hline 16 & & & 249 & 124 & 1866 \\
& & & \pm 23 & \pm 12 & \pm 174 \\
\hline
\end{tabular}

Note: *- The number of allowed heterozygous SNPs in ROH

\section{ROH identification based on Plink tool}

212 Plink software is widely used for $\mathrm{ROH}$ identification. Therefore, it was applied to estimate a possible data bias due to different software tools being used. It turn out, that the mean number

214 of ROH obtained with Plink was $74.9 \pm 1.9$, which was significantly less of those calculated

215 with detectRUNS based on sliding runs $(\mathrm{P}<0.001)$. The fact, that Plink identified less $\mathrm{ROH}$ 216 segments mainly in 1-2 Mb class than detectRUNS led to a larger mean ROH length in this 
217 class (S6 Table vs. S3 Table and S5 Table). Thus, the data obtained for the shortest ROH

218 length class is highly dependent on the software and parameters used.

\section{Comparative analysis of consecutive and sliding runs}

220 Comparative analysis of the consecutive and sliding data led to the following conclusions. If 221 heterozygous SNPs were disallowed the consecutive runs identified slightly more ROH than 222 sliding runs $(94.4 \pm 2.7$ vs. $86.0 \pm 2.8, \mathrm{P}<0.05)$. The shorter SNPs window at sliding runs or minimal number of SNPs needed to define segment at consecutive runs were, the more abundant in the ROH number was 1-2 Mb class (Table 2 and Table 4 vs. S2 Table and S6 Table). If the number of allowed heterozygous SNPs in ROHs continued to increase, the distribution of ROH segments peaked faster (on the number of heterozygous SNPs scale) when the sliding runs were used (Fig 1 vs. Fig 2). Necessary to note that the distributions based on consecutive runs had several ROH maximum (Fig 1) while those based on sliding runs had only two ROH maximum (Fig 2). There are further points to be made here. The cow genome had been filled in with $\mathrm{ROH}$ segments when sixteen heterozygous SNPs were allowed at sliding runs while their number was increased up to 240 for consecutive runs (Fig 3). Further, as it is shown on Fig 3, the sliding method identified the less number of ROH segments with smaller number of allowed heterozygous SNPs. Summarizing comparative analysis of both methods, we can conclude the large differences between findings of these methods. In the section below will be discussed how the ROH segments are distributed in cow genome.

\section{Evaluation of the distances between ROH segments}

The number of allowed heterozygous SNPs might be converted into nucleotide distance. For example, the distances between two non-interrupted by heterozygous SNPs ROH segments

(niROH) separated by one heterozygous SNP will be equal to the mean distance between 
241 SNPs in the cow genome multiplied by two. If two heterozygous SNP were allowed then,

242 either the distances between three niROH would be the same as for one heterozygous SNP or

243 it would be double of mean length between SNPs in genome, plus yet one mean distance, if

244 two niROH were separated by two heterozygous SNPs. Anyway, if the number of allowed

245 heterozygous SNPs was being continued to increase, the mean distance between niROH also

246 was increasing. That is the number of allowed heterozygous SNPs may be used as a measure

247 of the distance between niROH. Summarizing the above mentioned reasoning, the upper limit

248 of distance between niROH segments will be $\mathrm{D}=(\mathrm{n}+1) \mathrm{m}$, where $\mathrm{n}$ is the number of allowed

249 heterozygous SNPs and $\mathrm{m}$ is the mean distance between SNPs in cow genome equal to 52.1

$250 \mathrm{~Kb}(2508.706681 \mathrm{Mb}$ (genome length covered by SNPs) / 48108 (number of genotyped

251 SNPs) $=52.1 \mathrm{~Kb}$ ). Based on this formula it is possible to provide some estimates for each

252 length class about maximum and minimum distance between niROH and their length in $\mathrm{ROH}$

253 clusters. For each class there was a threshold beyond of which being impossible to form a

$254 \mathrm{ROH}$ clusters from niROH that would not exceed the maximum length for this class. Then, a

255 longer length class will begin to form. But, SNPs unevenly located in the cow genome [26].

256 Owing to this phenomenon and different length of niROHs, the number of heterozygous

257 SNPs suitable for every class length limit would be hardly to predict if not based on the mean

258 distances between SNPs.

\section{Calculation of the distances between ROH segments}

260 Let us calculate upper and lower limits between niROH in the length classes. If one

261 heterozygous SNP was allowed then mean distance between two niROH segments would be

$262104 \mathrm{~Kb}$ and those niROH form an initial $\mathrm{ROH}$ clusters. If eight heterozygous SNPs were

263 allowed, then different number of niROH segments might formed the ROH clusters 
between two niROH will be $450 \mathrm{~Kb}$. Otherwise, this distance should begin to decrease if the number of niROH will increase. Given that maximum length $2 \mathrm{Mb}$ could not be exceeded for

$\mathrm{Kb}$ length niROH separated by eight $100 \mathrm{~Kb}$ heterozygous SNP segments. Based on Fig 1 it can be concluded, with an increase in the number of heterozygous SNPs over 8, the number of niROH clusters satisfying 1-2 Mb class began to decrease. Further increase in the number of heterozygous SNPs led to an increase in the number of ROH in the next class. The same calculation is valid for other length classes but each of them has its own maximal and minimal number of niROH and distances between them.

274 Since the distances between SNPs in the cattle genome vary considerably [27], some SNPs may be located extremely close to each other. It can be illustrated for 1-2 Mb class when more than 60 heterozygous SNPs were allowed (Table 2). Indeed, for 60 allowed

277 heterozygous SNPs in $\mathrm{ROH}$, summed mean distance between $60 \mathrm{niROH}$ would be $\approx 3.5 \mathrm{Mb}$, that exceeds the length $2 \mathrm{Mb}$ for $1-2 \mathrm{Mb}$ class. As it was mentioned above there were noticeable differences in results of two methods. The sliding window method underestimated the distances between $\mathrm{ROH}$ and, therefore, the position of the peaks were shifted and merged relative to those for consecutive runs (Fig 1 vs. Fig 2).Therefore, for these methods the number of $\mathrm{ROH}$ and distances between niROH considerably differed and obtained findings were inconsistent. Visualization of $\mathrm{ROH}$ formation owing to niROH clusters is illustrated on Fig S1 - S3, on which the BTA 28 was chosen having the smallest number of ROH segments. When heterozygous SNPs were disallowed, only niROH were identified on BTA 28 (Fig S1). These niROH segments 1-18 Mb length scattered along BTA 28. When one

287 heterozygous SNP was allowed, additional niROH clasters forming new short ROH segments can be seen on BTA 28 (Fig S2). Their length was mostly 1-2 Mb. As the number of 
heterozygous SNPs increased to two, new niROH clusters forming ROH segments different

length can be seen on the chromosome 28 (Fig S3).

\section{Distribution of ROH in the cow genome}

292 In order to evaluate the chromosomes with largest number of ROH segments, calculation of

293 ROH proportion in them based on normalization to each chromosome length was performed.

294 For both runs the ranked chromosomes list is given in Table 5. Of 29 chromosomes, the

295 highest proportion of ROHs was calculated at BTA14, BTA16, and BTA7 not BTA1

Table 5. Normalized proportion of ROH in the cow chromosomes

\begin{tabular}{l|c|c|c|c|c|c|c|c|c|c}
\hline Chromosome & 14 & 16 & 7 & 26 & 8 & 13 & 1 & 22 & 17 & 4 \\
\hline $\begin{array}{l}\text { Consecutive } \\
\text { runs* }\end{array}$ & 1.350 & 1.280 & 1.240 & 1.200 & 1.190 & 1.120 & 1.110 & 1.098 & 1.060 & 1.050 \\
\hline Sliding runs & 1.388 & 1.295 & 1.218 & 1.170 & 1.169 & 1.161 & 1.086 & 1.011 & 1.050 & 1.030 \\
\hline Chromosome & 20 & 6 & 19 & 21 & 3 & 24 & 10 & 12 & 11 & 5 \\
\hline $\begin{array}{l}\text { Consecutive } \\
\text { runs }\end{array}$ & 1.024 & 1.018 & 1.016 & 0.964 & 0.955 & 0.929 & 0.928 & 0.926 & 0.920 & 0.911 \\
\hline Sliding runs & 0.980 & 0.999 & 1.010 & 0.965 & 0.963 & 0.955 & 0.931 & 0.918 & 0.909 & 0.911 \\
\hline Chromosome & 9 & 2 & 25 & 29 & 23 & 15 & 18 & 27 & 28 & \\
\hline $\begin{array}{l}\text { Consecutive } \\
\text { runs }\end{array}$ & 0.908 & 0.900 & 0.876 & 0.844 & 0.814 & 0.782 & 0.754 & 0.743 & 0.679 & \\
\hline Sliding runs & 0.902 & 0.898 & 0.920 & 0,865 & 0.851 & 0.800 & 0.743 & 0.774 & 0.680 & \\
\hline
\end{tabular}

297 Note: * The values of proportions were ranged from maximum to minimum only for

298 consecutive runs

299 (seventh position in the list), BTA2 (22th position in the list) and BTA3 (15th position in the

300 list). Thus, the number of $\mathrm{ROH}$ in chromosomes was not directly proportional to the

301 chromosome length. Spearman's correlation between consecutive and sliding runs data set

302 was $\mathrm{r}=1.0\left(\mathrm{P} \leq 2.0 \cdot 10^{-7}\right)$.

303 As can be seen on Fig 1 and Fig 2, for both methods the distributions of ROH number from

304 allowed number of the heterozygous SNPs within them was similar to normal. To measure a

305 proximity to the normal distribution Q-Q testing was used. It was shown their similarity to 
normal distribution but to varying degree for different length classes (S4 Fig -S13 Fig). It

307 should be borne in mind that for small samples a greater variation is expected. Obviously, the

308 distributions for classes 1-2 Mb, 2-4 Mb and 8-16 $\mathrm{Mb}$ had a positive skewness and light

309 tailed form, while for classes $8-16 \mathrm{Mb}$ and $>16 \mathrm{Mb}$ the distributions were the most similar to

310 normal except class $>16 \mathrm{Mb}$ for sliding runs (S13 Fig).

\section{Inbreeding}

312 To estimate a level of inbreeding in the herds, the mean inbreeding coefficient across herds was calculated (Table 6 and Table 7). If heterozygous SNPs were disallowed, then the mean inbreeding coefficients amounted to $0.111 \pm 0.003$ and $0.104 \pm 0.003$ for consecutive and

sliding runs respectively, and difference between them was insignificant. The $\mathrm{F}_{\mathrm{ROH}}$ estimated with Plink was $0.105 \pm 0.004$ what consistent with that for sliding runs. The largest variability of inbreeding was observed in fourth herd. This was mainly due to highly inbred cow in this herd. Exclusion this cow led to $F_{\mathrm{ROH}} 0.096 \pm 0.005$ and $0.089 \pm 0.005$ for consecutive and sliding runs. In this case, fourth herd significantly differed from herds 1 and herd $5(\mathrm{P}<0.01)$ and herd $2(\mathrm{P}<0.02)$, given t-test estimated with Bonferroni correction. It should be noted that in this herd insemination of the cows only from The Netherland bulls has occurred, while for other herds the bulls semen from North America and Canada were used as well. After excluding the highly inbreed cow from fourth herd, the average $F_{\mathrm{ROH}}$ in this herd became less than for other herds. This result indicates the correct selection of the bulls, even they were used from a single country. It was shown, the forth herd largely deviated from other herds when it was measured by fixation index and Principal Component Analysis [32].

327 When one heterozygous SNP was allowed in ROH, then $\mathrm{F}_{\mathrm{ROH}}$ were $0.145 \pm 0.003$ and $144 \pm$ 
330 herds, the heterozygous SNPs should not be allowed in ROH due to sizable bias. Distribution

331 of $\mathrm{F}_{\mathrm{ROH}}$ from the number of heterozygous SNPs is shown on Figure 4. Initially, a relatively

332 gradual increase of $\mathrm{F}_{\mathrm{ROH}}$ occurred. Then, an increasing greatly accelerated. Finally,

333 increasing gradually slowed down again. In fact, this curve indicated the relative distances

334 between niROH on heterozygous SNPs scale. From Fig 4 it can be seen that $20 \%$ of niROH

335 were located at short nucleotide distances less $1 \mathrm{Mb}, 80 \%$ of $\mathrm{ROH}$ clusters formed from

336 niROH were located at intermediate distances, and at least $20 \%$ of niROH clusters were

337 located at most longest distances. Thus, in the cow genome there is a complex hierarchical

338 structure of niROH clusters.

Table 6. Estimated mean ( \pm SE) inbreeding coefficient in the herds based on 20 SNPs

\begin{tabular}{|c|c|c|c|c|c|c|}
\hline Herd & 1 & 2 & 3 & 4 & 5 & 6 \\
\hline \multicolumn{7}{|l|}{ 0* } \\
\hline $\begin{array}{l}\text { Inbreeding } \\
\text { coefficient }\end{array}$ & $\begin{array}{l}0.117 \\
\pm 0.004 \\
\end{array}$ & $\begin{array}{l}0.112 \\
\pm 0.002 \\
\end{array}$ & $\begin{array}{l}0.105 \\
\pm 0.002 \\
\end{array}$ & $\begin{array}{l}0.111 \\
\pm 0.016 \\
\end{array}$ & $\begin{array}{l}0.116 \\
\pm 0.003 \\
\end{array}$ & $\begin{array}{l}0.105 \\
\pm 0.003 \\
\end{array}$ \\
\hline Maximum & 0.0006 & 0.060 & 0.068 & 0.047 & 0.075 & 0.071 \\
\hline Minimum & 0.227 & 0.153 & 0.160 & 0.779 & 0.166 & 0.158 \\
\hline \multicolumn{7}{|l|}{1} \\
\hline $\begin{array}{l}\text { Inbreeding } \\
\text { coefficient }\end{array}$ & $\begin{array}{l}0.153 \\
\pm 0.006 \\
\end{array}$ & $\begin{array}{l}0.143 \\
\pm 0.002 \\
\end{array}$ & $\begin{array}{l}0.143 \\
\pm 0.002 \\
\end{array}$ & $\begin{array}{l}0.147 \\
\pm 0.018 \\
\end{array}$ & $\begin{array}{l}0.147 \\
\pm 0.002 \\
\end{array}$ & $\begin{array}{l}0.137 \\
\pm 0.003 \\
\end{array}$ \\
\hline Maximum & 0.003 & 0.091 & 0.091 & 0.072 & 0.104 & 0.102 \\
\hline Minimum & 0.367 & 0.184 & 0.184 & 0.908 & 0.191 & 0.192 \\
\hline \multicolumn{7}{|l|}{2} \\
\hline $\begin{array}{l}\text { Inbreeding } \\
\text { coefficient }\end{array}$ & $\begin{array}{l}0.208 \\
\pm 0.008 \\
\end{array}$ & $\begin{array}{l}0.195 \\
\pm 0.002 \\
\end{array}$ & $\begin{array}{l}0.189 \\
\pm 0.002 \\
\end{array}$ & $\begin{array}{l}0.198 \\
\pm 0.017 \\
\end{array}$ & $\begin{array}{l}0.199 \\
\pm 0.002 \\
\end{array}$ & $\begin{array}{l}0.190 \\
\pm 0.003 \\
\end{array}$ \\
\hline Maximum & 0.010 & 0.139 & 0.148 & 0.102 & 0.158 & 0.155 \\
\hline Minimum & 0.511 & 0.235 & 0.229 & 0.948 & 0.240 & 0.246 \\
\hline \multicolumn{7}{|l|}{4} \\
\hline $\begin{array}{l}\text { Inbreeding } \\
\text { coefficient }\end{array}$ & $\begin{array}{l}0.384 \\
\pm 0.011 \\
\end{array}$ & $\begin{array}{l}0.372 \\
\pm 0.002 \\
\end{array}$ & $\begin{array}{l}0.369 \\
\pm 0.002 \\
\end{array}$ & $\begin{array}{l}0.377 \\
\pm 0.01 \\
\end{array}$ & $\begin{array}{l}0.376 \\
\pm 0.002 \\
\end{array}$ & $\begin{array}{l}0.369 \\
\pm 0.002 \\
\end{array}$ \\
\hline Maximum & 0.053 & 0.317 & 0.333 & 0.229 & 0.349 & 0.333 \\
\hline Minimum & 0.742 & 0.407 & 0.406 & 0.972 & 0.416 & 0.410 \\
\hline \multicolumn{7}{|l|}{8} \\
\hline $\begin{array}{l}\text { Inbreeding } \\
\text { coefficient }\end{array}$ & $\begin{array}{l}0.787 \\
\pm 0.008 \\
\end{array}$ & $\begin{array}{l}0.788 \\
\pm 0.001 \\
\end{array}$ & $\begin{array}{l}0.788 \\
\pm 0.001 \\
\end{array}$ & $\begin{array}{l}0.791 \\
\pm 0.005 \\
\end{array}$ & $\begin{array}{l}0.790 \\
\pm 0.001 \\
\end{array}$ & $\begin{array}{l}0.788 \\
\pm 0.001 \\
\end{array}$ \\
\hline Maximum & 0.396 & 0.763 & 0.764 & 0.667 & 0.773 & 0.772 \\
\hline Minimum & 0.934 & 0.809 & 0.813 & 0.981 & 0.814 & 0.808 \\
\hline 16 & & & & & & \\
\hline
\end{tabular}




\begin{tabular}{|c|c|c|c|c|c|c|}
\hline $\begin{array}{l}\text { Inbreeding } \\
\text { coefficient }\end{array}$ & $\begin{array}{l}0.9399 \\
\pm 0.0009 \\
\end{array}$ & \begin{tabular}{|l|}
0.9395 \\
\pm 0.0002 \\
\end{tabular} & \begin{tabular}{|l|}
0.9391 \\
\pm 0.0002 \\
\end{tabular} & \begin{tabular}{|l|}
0.9399 \\
\pm 0.001 \\
\end{tabular} & $\begin{array}{l}0.9397 \\
\pm 0.0002 \\
\end{array}$ & $\begin{array}{l}0.9391 \\
\pm 0.0002 \\
\end{array}$ \\
\hline Maximum & 0.903 & 0.934 & 0.935 & 0.924 & 0.936 & 0.936 \\
\hline Minimum & 0.964 & 0.944 & 0.944 & 0.985 & 0.943 & 0.943 \\
\hline \multicolumn{7}{|l|}{20} \\
\hline $\begin{array}{l}\text { Inbreeding } \\
\text { coefficient }\end{array}$ & $\begin{array}{l}0.9492 \\
\pm 0.0008\end{array}$ & $\begin{array}{ll}0.9488 \\
\pm 0.0002 \\
\end{array}$ & \begin{tabular}{|l|}
0.9487 \\
\pm 0.0002 \\
\end{tabular} & $\begin{array}{l}0.9495 \\
\pm 0.0009 \\
\end{array}$ & $\begin{array}{l}0.9489 \\
\pm 0.0002\end{array}$ & $\begin{array}{l}0.9488 \\
\pm 0.0002\end{array}$ \\
\hline Maximum & 0.919 & 0.945 & 0.945 & 0.938 & 0.946 & 0.945726 \\
\hline Minimum & 0.971 & 0.953 & 0.952 & 0.987 & 0.953 & 0.952828 \\
\hline \multicolumn{7}{|l|}{100} \\
\hline $\begin{array}{l}\text { Inbreeding } \\
\text { coefficient }\end{array}$ & $\begin{array}{l}0.9814 \\
\pm 0.0002 \\
\end{array}$ & $\begin{array}{l}0.98124 \\
\pm 0.00009 \\
\end{array}$ & \begin{tabular}{|l|}
0.98117 \\
\pm 0.00009 \\
\end{tabular} & \begin{tabular}{|l|}
0.9814 \\
\pm 0.0002 \\
\end{tabular} & $\begin{array}{l}0.98115 \\
\pm 0.00008 \\
\end{array}$ & $\begin{array}{l}0.9814 \\
\pm 0.0001 \\
\end{array}$ \\
\hline Maximum & 0.975 & 0.979 & 0.979 & 0.978 & 0.980 & 0.979 \\
\hline Minimum & 0.986 & 0.983 & 0.982 & 0.990 & 0.982 & 0.983 \\
\hline \multicolumn{7}{|l|}{240} \\
\hline $\begin{array}{l}\text { Inbreeding } \\
\text { coefficient }\end{array}$ & $\begin{array}{l}0.9872 \\
\pm 0.0001 \\
\end{array}$ & \begin{tabular}{|l|}
0.98641 \\
\pm 0.00007 \\
\end{tabular} & \begin{tabular}{|l|}
0.98635 \\
\pm 0.00007 \\
\end{tabular} & \begin{tabular}{|l|}
0.9864 \\
\pm 0.0001 \\
\end{tabular} & $\begin{array}{l}0.98626 \\
\pm 0.00007 \\
\end{array}$ & $\begin{array}{l}0.98642 \\
\pm 0.00007 \\
\end{array}$ \\
\hline Maximum & 0.983 & 0.984 & 0.985 & 0.985 & 0.985 & 0.985 \\
\hline Minimum & 0.989 & 0.988 & 0.987 & 0.990 & 0.988 & 0.988 \\
\hline
\end{tabular}

341 Note: * - The number of allowed heterozygous SNPs in ROH

342 Table 7. Estimated mean ( \pm SE) inbreeding coefficient in the herds based on 20 SNPs

343 sliding runs

\begin{tabular}{|c|c|c|c|c|c|c|}
\hline Herd & 1 & 2 & 3 & 4 & 5 & 6 \\
\hline \multicolumn{7}{|c|}{ Zero heterozygous SNP in $\mathrm{ROH}$} \\
\hline $\begin{array}{l}\text { Inbreeding } \\
\text { coefficient }\end{array}$ & $\begin{array}{l}0.110 \\
\pm 0.004\end{array}$ & $\begin{array}{l}0.105 \\
\pm 0.002\end{array}$ & $\begin{array}{l}0.098 \\
\pm 0.002\end{array}$ & $\begin{array}{l}0.103 \\
\pm 0.015\end{array}$ & $\begin{array}{l}0.109 \\
\pm 0.003\end{array}$ & $\begin{array}{l}0.098 \\
\pm 0.003\end{array}$ \\
\hline Minimum & 0.0003 & 0.055 & 0.063 & 0.040 & 0.070 & 0.065 \\
\hline Maximum & 0.204 & 0.146 & 0.153 & 0.739 & 0.158 & 0.151 \\
\hline \multicolumn{7}{|c|}{ One heterozygous SNP in $\mathrm{ROH}$} \\
\hline $\begin{array}{l}\text { Inbreeding } \\
\text { coefficient }\end{array}$ & $\begin{array}{l}0.154 \\
\pm 0.007\end{array}$ & $\begin{array}{l}0.143 \\
\pm 0.002\end{array}$ & $\begin{array}{l}0.137 \\
\pm 0.002\end{array}$ & $\begin{array}{l}0.146 \\
\pm 0.018\end{array}$ & $\begin{array}{l}0.148 \\
\pm 0.002\end{array}$ & $\begin{array}{l}0.138 \\
\pm 0.003\end{array}$ \\
\hline Minimum & 0.002 & 0.092 & 0.094 & 0.071 & 0.104 & 0.104 \\
\hline Maximum & 0.392 & 0.186 & 0.184 & 0.938 & 0.192 & 0.194 \\
\hline \multicolumn{7}{|c|}{ Two heterozygous SNP in $\mathrm{ROH}$} \\
\hline $\begin{array}{l}\text { Inbreeding } \\
\text { coefficient }\end{array}$ & $\begin{array}{l}0.227 \\
\pm 0.01 \\
\end{array}$ & $\begin{array}{l}00.213 \\
\pm 0.002 \\
\end{array}$ & $\begin{array}{l}0.207 \\
\pm 0.002 \\
\end{array}$ & $\begin{array}{l}0.217 \\
\pm 0.018 \\
\end{array}$ & $\begin{array}{l}0.217 \\
\pm 0.002 \\
\end{array}$ & $\begin{array}{l}0.208 \\
\pm 0.003 \\
\end{array}$ \\
\hline Minimum & 0.010 & 0.157 & 0.167 & 0.108 & 0.173 & 0.173 \\
\hline Maximum & 0.583 & 0.254 & 0.244 & 0.980 & 0.254 & 0.258 \\
\hline \multicolumn{7}{|c|}{ Four heterozygous SNP in $\mathrm{ROH}$} \\
\hline $\begin{array}{l}\text { Inbreeding } \\
\text { coefficient }\end{array}$ & $\begin{array}{l}0.474 \\
\pm 0.012 \\
\end{array}$ & $\begin{array}{l}0.463 \\
\pm 0.002 \\
\end{array}$ & $\begin{array}{l}0.461 \\
\pm 0.002 \\
\end{array}$ & $\begin{array}{l}0.470 \\
\pm 0.012 \\
\end{array}$ & $\begin{array}{l}0.467 \\
\pm 0.002 \\
\end{array}$ & $\begin{array}{l}0.463 \\
\pm 0.002 \\
\end{array}$ \\
\hline Minimum & 0.072 & 0.417 & 0.417 & 0.298 & 0.439 & 0.429 \\
\hline Maximum & 0.859 & 0.503 & 0.504 & 0.989 & 0.502 & 0.506 \\
\hline \multicolumn{7}{|c|}{ Eight heterozygous SNP in $\mathrm{ROH}$} \\
\hline Inbreeding & 0.924 & 0.929 & 0.928 & 0.930 & 0.930 & 0.929 \\
\hline
\end{tabular}




\begin{tabular}{l|l|l|l|l|l|l}
\hline coefficient & \pm 0.007 & \pm 0.0005 & \pm 0.0007 & \pm 0.003 & \pm 0.0006 & \pm 0.0007 \\
\hline Minimum & 0.562 & 0.918 & 0.915 & 0.826 & 0.921 & 0.919 \\
\hline Maximum & 0.988 & 0.940 & 0.941 & 0.100 & 0.942 & 0.942 \\
\hline \multicolumn{7}{c}{ Twelve heterozygous SNP in ROH } \\
\hline $\begin{array}{c}\text { Inbreeding } \\
\text { coefficient }\end{array}$ & 0.988 & 0.989 & 0.989 & 0.989 & 0.989 & 0.989 \\
\pm 0.0005 & $\pm 4.6 \cdot 10^{-5}$ & $\pm 6.15 \cdot 10^{-5}$ & \pm 0.0001 & $\pm 6.16 \cdot 10^{-5}$ & $\pm 5.58 \cdot 10^{-5}$ \\
\hline Minimum & 0.961 & 0.987 & 0.988 & 0.985 & 0.987 & 0.988 \\
\hline Maximum & 0.9898 & 0.9897 & 0.9897 & 0.9898 & 0.9898 & 0.9896 \\
\hline \multicolumn{7}{c}{ Sixteen heterozygous SNP in ROH } \\
\hline $\begin{array}{l}\text { Inbreeding } \\
\text { coefficient }\end{array}$ & 0.989824 & 0.989824 & 0.989824 & 0.989824 & 0.989824 & 0.989824 \\
\hline Minimum & NA & NA & NA & NA & NA & NA \\
\hline Maximum & NA & NA & NA & NA & NA & NA \\
\hline
\end{tabular}

\section{Discussion}

346 Over past decade the ROH approach has been widely used both on humans [3] and farm

347 animals [2]. Hallmark of $\mathrm{ROH}$ studies is a lot of software and thresholds criteria to be used in

348 them. The most widely applied software tools to identify ROH stretches are either sliding

349 window or consecutive runs. We preferred detectRUNS where both approach were

350 implemented [9]. The consecutive runs resulted in the average number of ROH $94.4 \pm 2.7$

351 while sliding runs $86.0 \pm 2.6$. This values for North American [8], Italian [16], European

352 Holstein [21], and Polish Holstein Black-and White variety [28] are $82.3 \pm 9.8(\mathrm{SD}), 81.7 \pm$

$3539.7(\mathrm{SD}), 74.6 \pm 2.3(\mathrm{SE})$, and $53.3 \pm 7.3(\mathrm{SD})$ respectively. The first three values do not differ

354 significantly from our ones, while the value for Polish cattle considerably differs. It was

355 shown that allowance of even one heterozygous SNP in ROH significantly increases the

356 number of ROH by 56.9 and 60.7 points for consecutive and sliding runs respectively (Table

3571 and Table 3). A limited number of studies investigated the effect of allowed heterozygous

358 SNPs on ROH data. Howrigan et al. [13] recommended disallowing any heterozygous SNPs

359 in ROH, while Ferencakovic et al. [22] suggested the number of heterozygous SNPs allowed

360 should be determined separately for each ROH length of interest and for each SNPs density. 
361 The relative frequency of $\mathrm{ROH}$ number in different length classes for consecutive runs were $61.4 \%(1-2 \mathrm{Mb}), 19.8 \%(2-4 \mathrm{Mb}), 11.3 \%(4-8 \mathrm{Mb}), 5.5 \%(8-16 \mathrm{Mb})$ and (longer than 16 Mb) $1.9 \%$, while for sliding runs these values were $60 \%, 19.8 \%, 12.1 \%, 5.8 \%, 2.1 \%$. Thus,

364 the largest number of ROH was identified in the shortest 1-2 Mb class. By Plink-running of

365 the cow genome was identified the following frequency of $\mathrm{ROH}$ in five categories $52 \%(0-2$ $\mathrm{Mb}), 25 \%(2-4 \mathrm{Mb}), 14 \%(4-8 \mathrm{Mb}), 7 \%(8-16 \mathrm{Mb})$ and (longer than $16 \mathrm{Mb}) 2.5 \%$ whose distribution is slightly different from those identified with detectRUNS. For North American Holstein animals these values were $43.5 \%, 23.9 \%, 17.7 \%, 10.5 \%$, and $4.7 \%$ [8]. and Polish Holstein 21\%, 37.1\%, 23.1\%, 13.3, and 5.6\% [28]. Thus, when we used detectRUNS for genome scanning of our local Holsteinzied cows, we obtained an abundant number of short $\mathrm{ROH}$ resulted from haplotypes reflecting the ancient relationship within breeding animals. But, when we used Plink, the values were similar to those for American and Italian data. It should be considered that authors of the article [28] used cgaTOH software and their data considerably differ from other data. Whether this result was due to cgaTOH software or/and breeding management requires furthers analysis. Estimation of the true amount of short $\mathrm{ROH}$ is important, since $0.1-3 \mathrm{Mb} \mathrm{ROH}$ segments have the more number of deleterious variants than segments greater of $3 \mathrm{Mb}$ [20]. Furthermore, to evaluate genomic estimated breeding value (GEBV), the short $\mathrm{ROH}$ is important for genomic ROH-based relationship matrix $\left(\mathrm{G}_{\mathrm{ROH}}\right)$ construction [29]. According to our estimates, the most number of

$381 \mathrm{ROH}$ was in 1-2 Mb class, which included niROHs shorter than $1 \mathrm{Mb}$, located at short distances and forming 1-2 Mb length $\mathrm{ROH}$ clusters, thereby determining the structure of the cattle genome (Fig S1-S3). Finally, the results of the animal ROH genome scanning can substantially depend on not only from selection strategy, but software used. This fact should 
386 Currently evaluated with detectRUNS the mean inbreeding coefficient for six herds was

$3870.111 \pm 0.003$ and $0.104 \pm 0.003$. It is equal to $0.105 \pm 0.004$ based on Plink runs. These

388 values do not differ significantly (t-test). But, $\mathrm{F}_{\mathrm{ROH}}$ increased significantly $(\mathrm{P}<0.001)$ from

$3890.111 \pm 0.003$ to $0.145 \pm 0.003$, when one heterozygous SNP was allowed in ROH (Table 6).

390 However, Mastrangelo et al. [24] showed that the differences between $\mathrm{F}_{\mathrm{ROH}}$ estimated using one, two, and three heterozygous SNPs were very small in Italian Holstein $(0.042,0.045$, 0.049) when $\mathrm{F}_{\mathrm{ROH}}$ was estimated for $>4 \mathrm{Mb} \mathrm{ROH} . \mathrm{F}_{\mathrm{ROH}}$ for American Holstein was 0.12 in European [21], Italian [16], and Polish Holstein [26] these values were $0.108 \pm 0.006$ (SE), $0.116 \pm 0.001(\mathrm{SE})$, and $0.118 \pm 0.027(\mathrm{SD})$ respectively. In the studies cited above, $\mathrm{ROH}$ data were based on 50k arrays, thereby not shorter than $1 \mathrm{Mb} \mathrm{ROH}$ segments were identified. Thus, short $\mathrm{ROH}$ were underestimated that might be led to an inaccurate estimate of inbreeding occurred several tenth years ago. The accurate knowledge of inbreeding in the herds is necessary for both calculation of inbreeding trend and evaluation of the selection strategies. In short ROH the deleterious mutations may be concentrated [20]. To overcome this problem a high density arrays or whole genome sequencing (WGS) should be used. Comparing $50 \mathrm{~K}$ and $\mathrm{HD}$ panels provide evidence that data from $50 \mathrm{~K}$ panel lead to imprecise determination of short $\mathrm{ROH}$ segments [22]. However, detection the ROH based on highdensity or 50k chip data was shown to be able to give the estimates of current inbreeding the most similar to ROH values obtained from sequence data [30]. Bhali et al. [31] provided the 406 comprehensive WGS data for Branvich cattle. The medium - sized ROH $(0.1-2 \mathrm{Mb})$ were 407 the most frequent class $(50.46 \%)$ and contributed most $(75 \%)$ of the total genomic 408 inbreeding, while short ROH $50-100 \mathrm{~Kb}$ occurred almost as frequent (49.17\%) as medium409 sized $\mathrm{ROH}$, they contributed only $19.52 \%$ to total genomic inbreeding. These findings 410 provide an accurate estimate of short $\mathrm{ROH}$ in the cattle genome and their input to total 
inbreeding. The average $\mathrm{F}_{\mathrm{ROH}}$ estimated from WGS data was 0.14 in Branvich cattle. This

412 value is less than WGS $F_{\mathrm{ROH}}$ in Holstein 0.18 [31]. Thus, the results inferred from WGS

413 provide a larger $\mathrm{F}_{\mathrm{ROH}}$ than those from SNPs array $(0.15$ vs. 0.18). Thus, 50k panel can not

414 accurately capture inbreeding occurred several tenth years in the past.

415 It may be assumed that for a herd or population has to be an event horizon beyond, which it is

416 impossible to obtain only from $\mathrm{ROH}$ data valid information about their breeding history

417 events. Our local population with both reduced effective population size, ongoing admixture

418 and inbreeding throughout its breeding history, accompanied by recombination, should has

419 the greatest number of short $\mathrm{ROH}$ less than $1 \mathrm{Mb}$ in herds. These short $\mathrm{ROH}$ can be

420 considered as a relict $\mathrm{ROH}$ segments formed due to some population events, such as

421 admixture, drift, bottleneck, and inbreeding occurred many decades ago. Previously, with

422 Principal Component Analysis the bottleneck in our local herds was not proved [32]. An

423 accurate interpretation of these $\mathrm{ROH}$ can be troublesome without knowledge of the herd

424 management history. Nevertheless, it is very important to know the true number of short

425 ROHs at the animals analyzed (see above mentioned WGS data). Thus, the event horizon

426 might be depended as from pedigree information, ROH length profile (used SNPs array or

427 WGS) as well as on algorithm-defined approach for ROHs identification. However, ROH

428 segments shorter than $1 \mathrm{Mb}$ can be considered as being beyond the event horizon due to 429 significant shortening by recombination. An addition, short ROH characterized by strong LD

430 among markers are not always considered autozygous but, nevertheless, are due to mating to

431 distantly related animals [33]. Summarizing, it should be assume that inbreeding data based

432 on array can only be relatively correct for an $\mathrm{ROH}$ larger than $1 \mathrm{Mb}$ (no more 50 generation 433 back). 
435

436

437

438

439

440

441

442

443

444

445

446

447

448

449

450

451

452

453

454

455

456

457

458

459

In several studies have noticed an uneven distribution of $\mathrm{ROH}$ in the chromosomes [e.g. 10, $14,34]$. Giving the number of $\mathrm{ROH}$ in the chromosomes, their proportion normalized on each

chromosome length was calculated (Table 5). Of 29 chromosomes, the most fill in with ROH segments were BTA14, BTA16 and BTA7 for both runs approach used. Purfield at al. [17] noticed that the largest extent of overlapping $\mathrm{ROH}$ positions among studied breeds had $\mathrm{ROH}$ segments on BTA14 and BTA16. The genome regions with the highest frequency of ROH occurrence were called "ROH islands" $[35,36]$. The ROH islands on BTA14 and BTA16 were identified among Polish Holstein-Friesian animals [26]. In American Holstein ROH distribution was more variable among the genomes of selected animals in comparison to a more even $\mathrm{ROH}$ distribution at unselected animals [37]. Further, in this study more than 40 genetic regions under selection on BTA2, BTA7, BTA16 and BTA20 were identified. Regions with high level of ROH for American and New Zealand Jersey cows and bulls were detected on BTA3 and BTA7 [10]. One strongest ROH region common for Kholmogor and Holstein breeds and one region common for Yaroslavl and Holstein breeds was found on BTA14 and BTA16 [21]. An extremely non-uniform ROH patterns among bovine populations of Angus, Brown Swiss, and Fleckvieh breeds were mainly located on BTA6, BTA7, BTA16, and BTA21 [34]. On BTA7 was found the highest number of ROH islads among all Neilore breed lineages [38]. Furthermore, on BTA14 in dairy Gyr breed (Bos Indicus) has shown an enrichment of genes affecting traits of interest for dairy breeds [39]. Goszczynski et al. [40] analyzed $\mathrm{ROH}>16 \mathrm{Mb}$ (three generations since the common ancestor) in highly inbred Retinta bulls. Among other chromosomes the highest occurrence of ROH was found on BTA7. Summarizing studies cited above, it can be suggested that BTA7 is outstanding regarding $\mathrm{ROH}$ islands occurrence in the cattle genome but there is no overall direct relationship between frequency of $\mathrm{ROH}$ segments in chromosomes and identified $\mathrm{ROH}$ islands there. 
460 Having determined proportion of ROHs in the chromosomes, it is necessary to define a type

461 of distribution over which ROH segments located in genome. Considering the dependence of

462 the ROH number from the number of allowed heterozygous SNPs in them, promoted to

463 realize this task. For this, recalculation of the number of allowed heterozygous SNPs in ROH

464 into distances between niROH was performed. To further elucidate the structure of ROH

465

466

467

468

469

470

471

472

473

474

475

476

477

478

479

480

481

482

483 segments they were classified into five length classes. It turned out that in each class the number of $\mathrm{ROH}$ segments, which were formed from niROH were distributed similar to the normal distribution (Fig 1 and Fig 2). It was true for total set of ROH segments as well (Fig 3). This indicates a cluster structure of $\mathrm{ROH}$ in the cow genome. The ROH clusters form a hierarchical structure from short to longer as can be visualized on Fig S1-S3. As was shown, the number of short ROH was highly depended on the software and genotyping method used.

Moreover, we show that the consecutive runs more accurately identified $\mathrm{ROH}$ pattern in cow genome. Nevertheless, it would like to point out that both methods coincide in estimate of ROH distribution type being similar to normal. Taken together our findings it should be admit about uneven distribution $\mathrm{ROH}$ segments in the cow genome as a result of different population events occurred during it history.

\section{Conclusions}

Our analysis of the $\mathrm{ROH}$ data was able to estimate that consecutive runs the most accurately identified $\mathrm{ROH}$ in the cow genome. It was shown that missing SNPs had not sizable effect on the number of $\mathrm{ROH}$, while an allowance of even one heterozygous SNP in ROH had significant effect. Therefore, caution should be taken to allow any number of heterozygous SNPs in ROH. The mean inbreeding coefficient for our local herds was $0.111 \pm 0.003$, which was not differ from those for the Holstein breed over the world. It was suggested that ROH segments had a tendency for clustering in the cow genome. Distribution of ROH clusters in 
the cow genome was similar to normal. Moreover, the number of ROH segments in the

485 chromosomes did not depend on their length and the most abundant in ROH segments were

486 BTA14, BTA7, and BTA18.

487

\section{Author contribution}

\section{References}

489

490

491

492

493

494

495

496

497

498

499

500

501

502

503

504

505

1. Meuwissen T, Luo Z. Computing inbreeding coefficient in large populations. Genet Sel Evol. 1992; 24(4): 305-313. doi.org/10.1186/1297-9686-24-4-305

2. Peripolli E, Munari DP, Silva MVGB, Lima ALF, Irgang R, Baldi F. Runs of homozygosity: current knowledge and applications in livestock. Animal Genet. 2016; 48: 255-271. doi: 10.1111/age.12526.

3. Ceballos FC, Joshi PK, Clark DW, Ramsay M, Wilson JF. Runs of homozygosity: windows into population history and trait architecture. Nat Rev Genet. 2018;19(4):220234. doi: $10.1038 / \operatorname{nrg} .2017 .109$

4. Gusev A, Lowe JK, Stoffel M, Daly MJ, Altshuler D, Breslow JL, Friedman JM, Peer I. Whole population, genome-wide mapping of hidden relatedness. Genome Res. 2009; 19: 318-326. doi: 10.1101/gr.081398.108

5. Browning SR, Browning BL. High-resolution detection of identity by descent in unrelated individuals. Am J Hum Genet. 2010; 86: 526-539. doi: 10.1016/j.ajhg.2010.02.021

6. Narasimhan V, Danecek P, Scally A, Xue Y, Tyler-smith C, Durbin R. Application note BCFtools / ROH: a hidden Markov model approach for detecting autozygosity from nextgeneration sequencing data. Bioinformatics. 2016; 32(11): 1749-1751. doi: 
7. Purcell S, Neale B, Todd-Brown K, et al. PLINK: a tool set for whole-genome association and population-based linkage analyses. Am J Hum Genet. 2007; 81: 559-575. doi:

8. Forutan M, Mahyari SA, Baes C, Melzer N, Schenkel FS, Sargolzaei M. Inbreeding and runs of homozygosity before and after genomic selection in North American Holstein cattle. BMC Genomics. 2018; 19:98. DOI 10.1186/s12864-018-4453-z

9. Biscarini F, Paolo Cozzi P, Gaspa G, Marras G. detectRUNS: Detect Runs of homozygosity and runs of heterozygosity in diploid genomes. R package version 0.9.6. 2020; Retrieved from https://CRAN.Rproject.org/package=detectRUNS

10. Howard JT, Maltecca C, Haile-Mariam M, Hayes BJ, Pryce JE. Characterizing homozygosity across United States, New Zealand and Australian Jersey cow and bull populations. BMC Genomics. 2015; 16: 187. DOI 10.1186/s12864-015-1352-4

11. Kim E-S, Sonstegard TS, Van Tassell CP, Wiggans G, Rothschild MF. The relationship between runs of homozygosity and inbreeding in Jersey cattle under selection. PLoS One.

12. Zhang L, Orloff MS, Reber S, Li S, Zhao Y, Eng C. CGATOH: extended approach for identifying tracts of homozygosity. PLoS One. 2013; 8: e57772. 2015; 10: e0129967. doi: 10.1371/journal.pone.0129967

524 13. Howrigan DP, Simonson MA, Keller MC. Detecting autozygosity through runs of 525 homozygosity: a comparison of three autozygosity detection algorithms. BMC Genomics. 2011; 12: 460. http://www.biomedcentral.com/1471-2164/12/460 
527

528

529

530

531

532

533

534•

535

536

537

538

539

540

541

542

543

544

545

546

547

14. Ferencakovic M, Hamzic E, Gredler B, Curik I, Johann S. Runs of homozygosity reveal genome-wide autozygosity in the Austrian Fleckvieh cattle. Agriculturae Conspectus Scientificus (ACS). 2011; 76(4): 325-329.

15. Bjelland DW, Weigel KA, Vukasinovic N, Nkrumah JD. Evaluation of inbreeding depression in Holstein cattle using whole-genome SNP markers and alternative measures of genomic inbreeding. J Dairy Sci. 2013; 96(7): 4697-4706. doi: 10.3168/jds.20126435

16. Marras G, Gaspa G, Sorbolini S, Dimauro C, Ajmone-Marsan P, Valentini A, Williams JL, Macciotta NPP. Analysis of runs of homozygosity and their relationship with inbreeding in five cattle breeds farmed in Italy. Animal Genet. 2014; 46: 110-121.

DOI: $\underline{10.1111 / \text { age.12259 }}$

17. Purfield DC, Berry D, McParland S, Bradley DG. Runs of homozygosity and population history in cattle. BMC Genetics. 2012; 13: 70. doi: 10.1186/1471-2156-13-70

18. Karimi Z. Runs of homozygosity patterns in taurine and indicine cattle breeds. Doctoral thesis, University of Natural Resources and Life Sciences, Vienna. 2013.

19. Zavarez LB, Utsunomiya YT, Carmo AS, Neves HHR, Carvalheiro R, Ferencalkovic M, et al. Assessment of autozygosity in Nellore cows (Bos indicus) through high density SNP genotypes. Frontiers in Genetics. 2015; 6: 5. doi: 10.3389/fgene.2015.00005

20. Zhang Q, Guldbrandtsen B, Bosse M, Lund MS, Sahana G. Runs of homozygosity and distribution of functional variants in the cattle genome. BMC Genomics. 2015; 16: 542. doi: $10.1186 / \mathrm{s} 12864-015-1715-\mathrm{x}$. 
548 21. Zinovieva NA, Dotsev AV, Sermyagin AA, Deniskova TE, Abdelmanova AS,

549 Kharzinova VR, et al. Selection signatures in two oldest Russian native cattle breeds revealed using high density single nucleotide polymorphism analysis. PLoS ONE. 2020; 15(11): e0242200. doi: 10.1371/journal.pone.0242200

552

553

554

555

556

557

558

559

560

561

562

563

564

565

566

567

568

22. Ferenčaković M, Sölkner J, Curik I. Estimating autozygosity from high-throughput information: effects of SNP density and genotyping errors. Genet Sel Evol. 2013; 45: 42. doi: 10.1186/1297-9686-45-42

23. Ceballos FC, Hazelhurst S, Ramsay M. Assessing runs of Homozygosity: a comparison

of SNP Array and whole genome sequence low coverage data. BMC Genomics. 2018; 19: 106. doi: $10.1186 / \mathrm{s} 12864-018-4489-0$

24. Mastrangelo S, Tolone M, Di Gerlando R, Fontanesi L, Sardina MT, Portolano B. Genomic inbreeding estimation in small populations: evaluation of runs of homozygosityin three local dairy cattle breeds. Animal. 2016; 10(5): 746-754. doi.org/10.1017/S1751731115002943

25. Addo S, Klingel S, Hinrichs D, Thaller G. Runs of homozygosity and NetView analyses provide new insigt into the genome -wide diversity and admixture of three German cattle breeds. PLoS ONE. 2019; 14(12): e0225847. doi: 10.1371/journal.pone.0225847

26. $\mathrm{R}$ Development Core Team R: a language and enviroment for statistical computing. $\mathrm{R}$ foundation for statistical computing. Viena. http://www.Rproject.org. Accessed 1 Dec 2019

27. Matukumalli LK, Cynthia T, Lawley CT, Robert D,. Schnabel RD, Taylor JF, et al. Development and characterization of a high density SNP genotyping assay for cattle. PLoS ONE. 2009; 4(4): e5350. doi:10.1371/journal.pone.0005350 
28. Szmatoła T, Gurgul A, Jasielczuk I, Zabek T, Ropka-Molik K, Litwinczuk Z, Bugnodoi.org/10.3390/ani9121024.

29. Luan T, Yu X, Dolezal M, Bagnato A, Meuwissen THE. Genomic prediction based on runs of homozygosity. Genet Sel Evol. 2014; 46: 64. doi: 10.1186/s12711-014-0064-6

30. Zhang Q, Calus MPL, Guldbrandtsen B, Lund MS, Sahana G. Estimation of inbreeding using pedigree, 50k SNP chip genotypes and full sequence data in three cattle breeds. BMC Genetics.2015; 16: 88. doi: 10.1186/s12863-015-0227-7

580

31. Bhati M, Kadri NK, Crysnanto D, Pausch H. Assesing genomic diversity and signatures of selection in Original Braunvich cattle using whole -genome sequencing data. BMC Genomics. 2020; 21: 27. doi: 10.1186/s12864-020-6446-y

32. Smaragdov MG, Kudinov AA. Assessing the power of principal components and wright's fixation index analyzes applied to reveal the genomewide genetic differences between herds of Holstein cows. BMC Genetics. 2020; 21: 47. doi.org/10.1186/s12863-

33. McKay SD, Schnabel RD, Murdoch BM, Matukumalli LK, Aerts J, Coppieters W, et al. Whole genome linkage disequilibrium maps in cattle. BMC Genetics. 2007; 8: 74. doi:10.1186/1471-2156-8-74 populations. 10th World Congr. Genet Appl Livest. Prod. 2014. 
593

594

595

596

597

598

599

600

601

602

603

604

605

606

607

608

609

610

611

612

613

614

35. Nothnagel M, Lu TT, Kayser M, Krawczak M. Genomic and geographic distribution of SNP-defined runs of homozygosity in Europeans. Hum Mol Genet. 2010; 19(15): 29272935. https://doi.org/10.1093/hmg/ddq198

36. Pemberton TJ, Absher D, Feldman MW, Myers RM, Rosenberg NA, Li JZ. Genomic patterns of homozygosity in worldwide human populations. Am J Hum Genet. 2012; 91(2): 275-292. doi: 10.1016/j.ajhg.2012.06.014

37. Kim ES, Cole JB, Huson H, Wiggans GR, van Tassel CP, Crooker BA, et al. Effect of artificial selection on runs of homozygosity in U.S. Holstein cattle. PLoS ONE. 2013; 8: e80813. doi.org/10.1371/journal.pone.0080813

38. Peripolli E, Metzger J, Antuner de Lemos MV, Stafuzza NB, Kluska S, Olivieri BF, et al. Autozygosity islands and ROH patterns in Nellore lineages: evidence of selection for functionally important traits. BMC Genomics. 2018; 19: 680. doi: 10.1186/s12864-018$5060-8$

39. Peripolli E, Stafuzza NB, Munari DP, Lima ALF, Irgang R, Machado MA, et al. Assessment of runs of homozygosity islands and estimates of genomic inbreeding in Gyr (Bos indicus) dairy cattle. BMC Genomics. 2018; 19: 34. doi: 10.1186/s12864-017-43653.

40. Goszczynski D, Molina A, Tera E, Morales-Durand H, Ross P, et al. Runs of homozygosity in a selected cattle population with extremely inbred bulls: Descriptive and functional analyses revealed highly variable patterns. PLoS ONE. 2018; 13(7): e0200069. doi: 10.1371/journal.pone.0200069.

\section{Supporting information}


615 S1 Table. Estimated mean $( \pm \mathrm{SE})$ ROH number in the herds based on 15 SNPs

616 consecutive runs.

$617(\mathrm{DOCX})$

618 S2 Table. Estimated mean ( \pm SE) across herds ROH number in length classes based on 61915 SNPs consecutive runs.

$620(\mathrm{DOCX})$

621 S3 Table. The mean ( \pm SE) across herds ROH length in the classes based on 20 SNPs

622 consecutive runs.

$623(\mathrm{DOCX})$

624 S4 Table. Estimated mean ( \pm SE) ROH number in the herds based on 15 SNPs sliding 625 runs.

$626(\mathrm{DOCX})$

627 S5 Table. The mean across herds ROH length in the classes based on 20 SNPs sliding 628 runs.

$629(\mathrm{DOCX})$

630 S6 Table. The mean $( \pm \mathrm{SE})$ across herds ROH length in the classes based on Plink runs.

$631(\mathrm{DOCX})$

632 Figures

633 S1 Fig. Distribution of ROH segments along BTA 28 based on consecutive runs.

634 Each row represents a cow from first herd and each column represents a genotyped SNPs

635 position. Each ROH is a niROH. The heterozygous SNPs were disallowed.

636 (PDF)

637 S2 Fig. Distribution of ROH segments along BTA 28 based on consecutive runs.

638 Each row represents a cow from first herd and each column represents a genotyped SNPs

639 position. Each ROH consists of some niROH number. One heterozygous SNPs were allowed.

$640 \quad(\mathrm{PDF})$

641 S3 Fig. Distribution of ROH segments along BTA 28 based on consecutive runs.

642 Each row represents a cow from first herd and each column represents a genotyped SNPs

643 position. Each ROH consists of some niROH number. Two heterozygous SNPs were

644 allowed. 
645 (PDF)

646 S4 Fig. Q-Q plot based on consecutive runs.

647 Distribution of $\mathrm{ROH}$ segments from 1-2 Mb class.

$648 \quad(\mathrm{PDF})$

649 S5 Fig. Q-Q plot based on consecutive runs.

650 Distribution of $\mathrm{ROH}$ segments from 2-4 Mb class.

651 (PDF)

652 S6 Fig. Q-Q plot based on consecutive runs.

653 Distribution of $\mathrm{ROH}$ segments from 4-8 Mb class.

654 (PDF)

655 S7 Fig. Q-Q plot based on consecutive runs.

656 Distribution of $\mathrm{ROH}$ segments from 8-16 Mb class.

657 (PDF)

658 S8 Fig. Q-Q plot based on consecutive runs.

659 Distribution of $\mathrm{ROH}$ segments from $>16 \mathrm{Mb}$ class.

660 (PDF)

661 S9 Fig. Q-Q plot based on sliding runs.

662 Distribution of ROH segments from 1-2 Mb class.

663 (PDF)

664 S10 Fig. Q-Q plot based on sliding runs.

665 Distribution of ROH segments from 2-4 Mb class.

666 (PDF)

667 S11 Fig. Q-Q plot based on sliding runs.

668 Distribution of $\mathrm{ROH}$ segments from 4-8 Mb class.

669 (PDF)

670 S12 Fig. Q-Q plot based on sliding runs.

671 Distribution of ROH segments from 8-16 Mb class. 
$672(\mathrm{PDF})$

673 S13 Fig. Q-Q plot based on sliding runs.

674 Distribution of $\mathrm{ROH}$ segments from $>16 \mathrm{Mb}$ class.

675 (PDF)

676

677

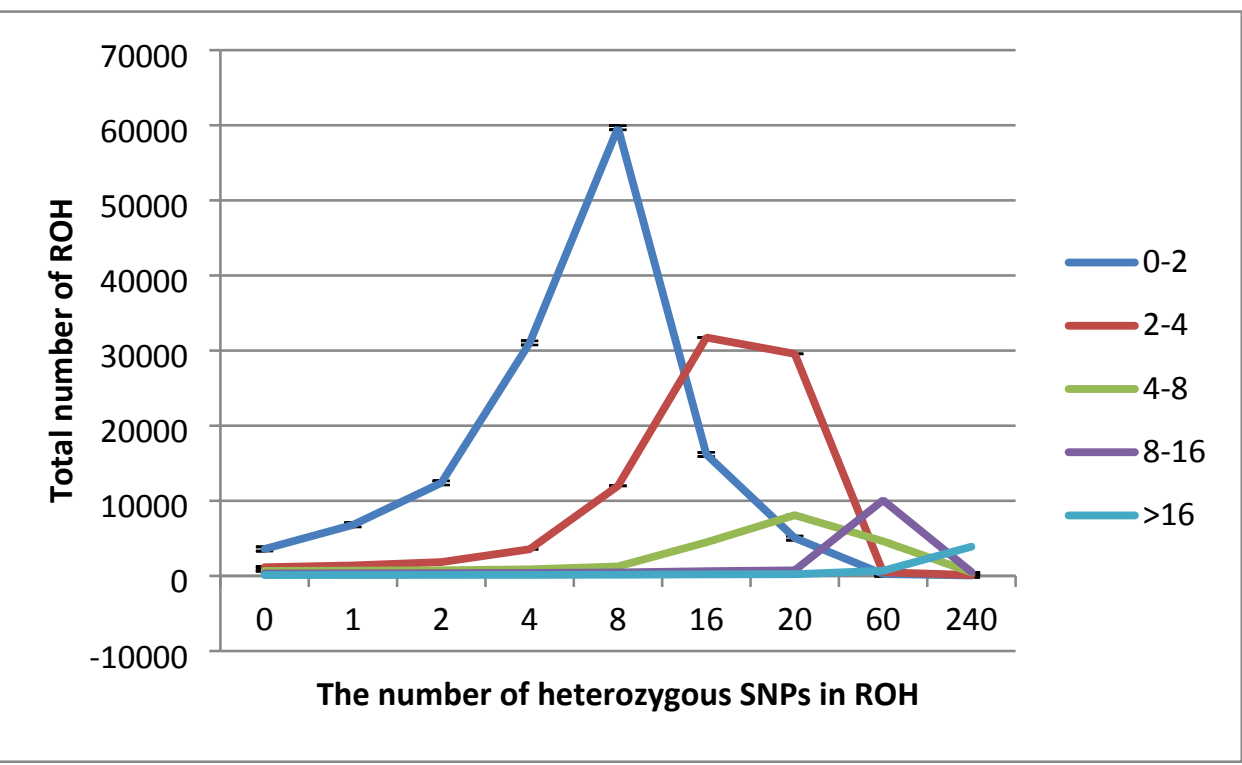

679 Figure 1. Distribution of ROH in five length classes based on consecutive runs

680

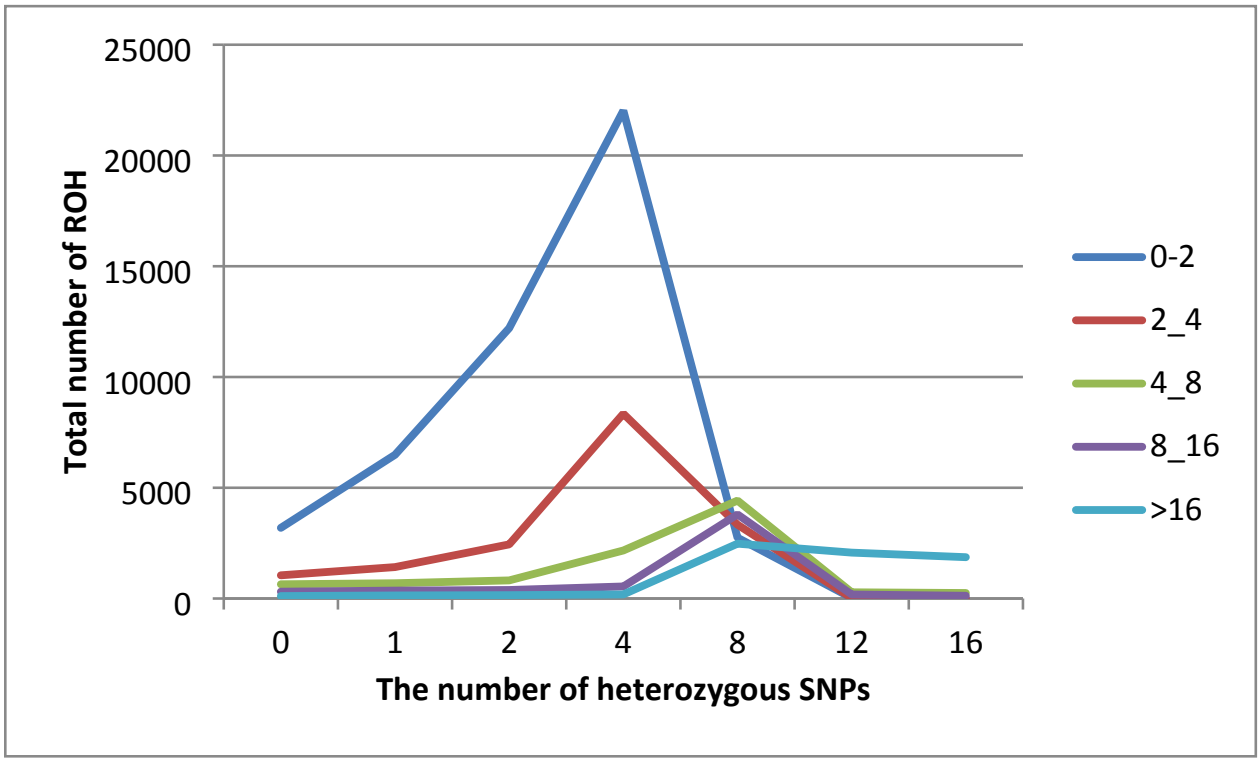

Figure 2. Distribution of $\mathrm{ROH}$ in five length classes based on sliding runs 


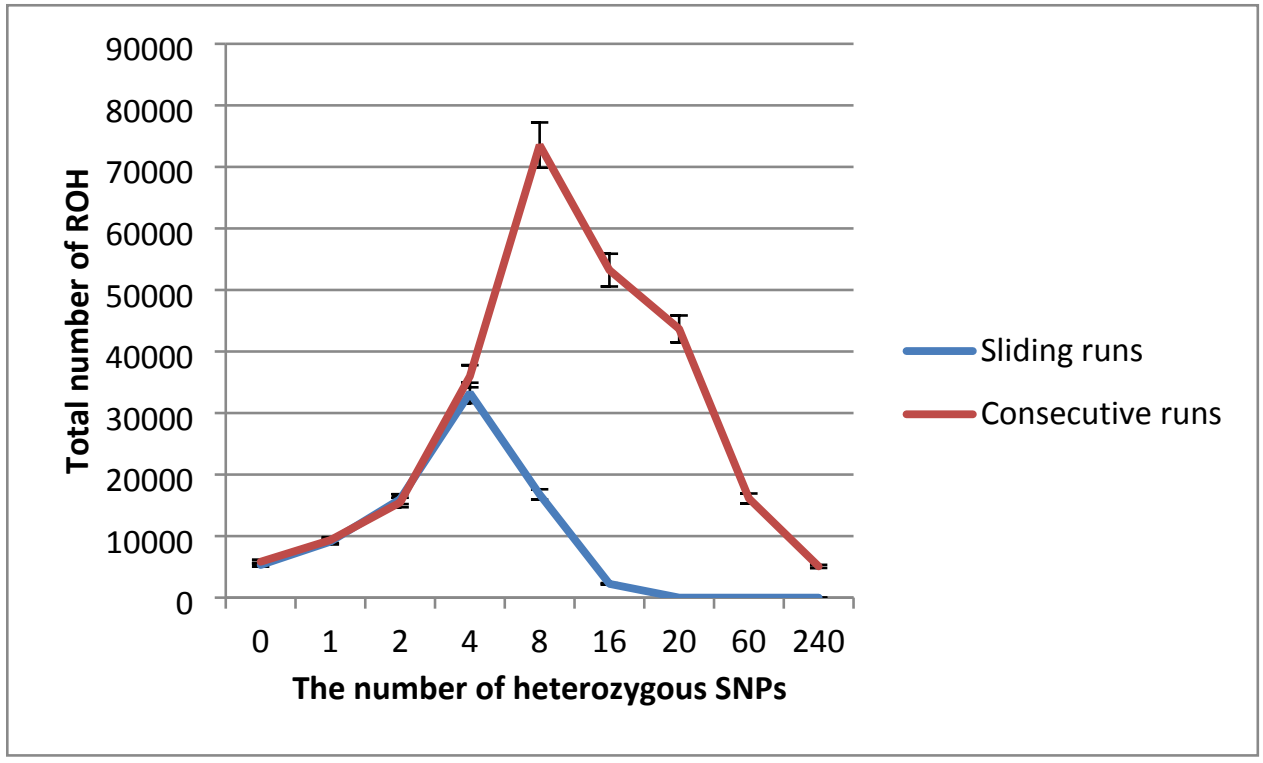

\section{Figure 3. Total distribution of ROH in the cow genome}

686

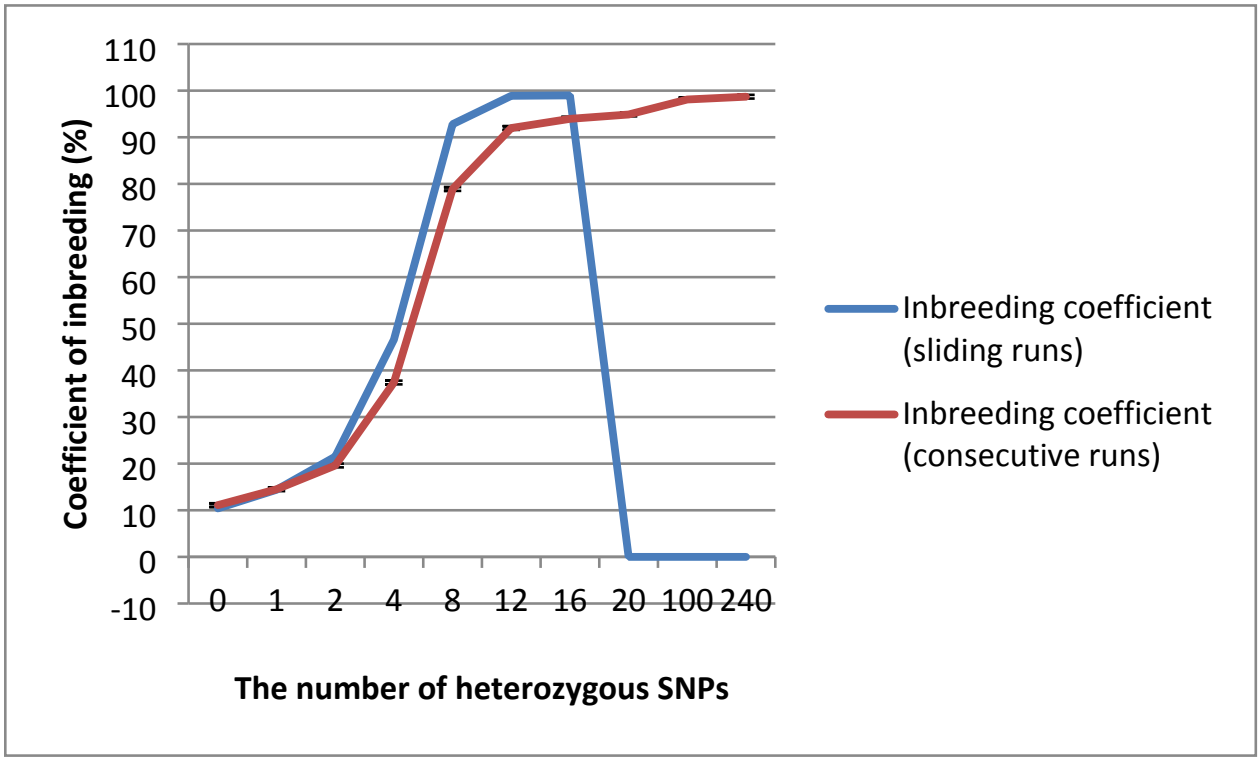

688 Figure 4. Dependence of the inbreeding coefficient on the number of heterozygous SNPs 